\title{
Carlos Cruz-Diez: \\ o acontecimento da cor
}

Bruna Gomes da Costa ${ }^{1}$

DOI 10.20396/eha.vil4.3375

O artista venezuelano Carlos Cruz-Diez (1923-2019) foi um dos principais nomes da pósmodernidade a levar a cabo a pesquisa da cor nas artes visuais. Nascido em Caracas, ele ingressa na Escuela de Artes Plásticas y Aplicadas em 1940, onde inicia sua produção pictórica. A despeito do que se conhece hoje como a obra do artista, seus primeiros trabalhos são figurativos e narrativos. Isso se deve principalmente pelos ensinamentos acadêmicos que na época haviam absorvido e estabelecido o Impressionismo como a linguagem mais apropriada a ser seguida e Cézanne como influência principal. No entanto, mesmo esta produção inicial - cujas imagens são raras - podemos notar um crescente interesse no uso das cores vibrantes.

Ainda na Academia, durante as aulas de pintura de paisagem, o artista se lembra de um episódio que foi crucial para sua relação com as cores posteriormente. Durante uma aula com o professor Rafael Ramón Conzález, a turma foi levada ao parque El Calvario, no centro histórico de Caracas, para prática de pintura de paisagem.

Tinha escolhido a perspectiva de uma curva onde se via a calçada e um grupo de árvores ao fundo. Eu havia apoiado o papel-cartão numa árvore, porque ainda não podia usar um cavalete. Desenhei a perspectiva e comecei a pintar o pavimento com preto e branco, para fazer um cinza. Nesse momento, Rafael Ramón se aproximou e me disse: “Como vai fazer isso, rapaz? Não está vendo esses matizes maravilhosos, esses lilases, esses verdes, azuis e rosas que estão no cinza e nas sombras?". Levei um susto danado, porque me achei completamente cego. No dia seguinte, voltei à paisagem determinado a descobrir as cores que o professor me havia indicado. O sentimento de cegueira me deixou desconcertado durante muitos dias, até que, como uma revelação, recuperei minha capacidade de ver [grifo meu]. Eu estava vendo e, sobretudo, entendendo que não se tratava apenas de enxergar, mas de imaginar. Imaginar as cores. ${ }^{2}$

A partir desse evento, Cruz-Diez passa a pintar com o máximo de cores possível em suas telas (figura 01). Este sentimento de cegueira e de posterior "recuperação da capacidade de ver" através

\footnotetext{
1 Mestranda no Programa de Pós-Graduação em Artes Visuais da Universidade Federal do Rio de Janeiro na linha de pesquisa História e Crítica da Arte. Orientadora: Prof. ${ }^{\text {a }}$ Dr. ${ }^{\text {a Patrícia Corrêa. }}$

2 CRUZ-DIEZ, Carlos. Carlos Cruz-Diez conversa com Ariel Jiménez. São Paulo: Cosac Naify, 2014. p. 35.
} 
das cores é um dado essencial para os rumos seu trabalho, sobretudo nas obras públicas que realizou mais tarde, como veremos adiante.

Arte como engajamento social

Neste momento (década 1940), duas questões eram fundamentais para o artista: a autenticidade de seu trabalho, isto é, a criação de uma linguagem individual, e o compromisso público, uma espécie de dever com seu país e com seus possíveis espectadores. Afetava-o a situação de desigualdade social da Venezuela, explicitada sobretudo na capital, mesmo após um período de certo "impulsionamento econômico" vivido sob o regime do ditador Juan Vicente Gómez. O país estava assolado de problemas, mesmo possuindo tantas riquezas. Cruz-Diez queria contribuir com sua nação através do seu ofício, produzindo uma arte socialmente relevante e com crescente desejo de entrar para os anais da História. Nenhum dos grandes artistas venezuelanos que admirava na infância estava na História da Arte que o artista estudou na Academia. A partir de 1947, sua ideia foi realizar obras de cunho social e político, como um dever historicamente correto ${ }^{3}$. O problema da cor ainda não estava claro para ele, mas sempre buscou captar as luzes e cores que o fascinavam na paisagem venezuelana e na sua infância, ainda que atrelado a uma outra narrativa. $O$ artista nunca teve relação direta com nenhum partido, mas a maioria de seus colegas estava envolvida com o Partido Comunista, o que certamente o influenciou diretamente na vontade de retratar as mazelas da sociedade. No entanto, ele queria realizar sua pintura engajada sem estar propriamente comprometido com ninguém senão com seus ideais próprios ${ }^{4}$.

A narrativa e literalidade foram se revelando cada vez menos potentes na sua motivação e na inserção de sua obra num circuito artístico. No início dos anos 1950, em crise, ele deixou diversas obras inacabadas. Na mesma época, Jesús Soto, que havia migrado para Paris, enviou uma carta a Cruz-Diez contando sobre a descoberta de Mondrian, que influenciaria toda a obra do primeiro. Isso aumentou as dúvidas de Cruz-Diez, que acreditava que a função social da arte residia em comunicar de maneira narrativa um posicionamento. A abstração de Mondrian parecia-lhe fria e distante da realidade social ${ }^{5}$, sem a humanidade que ele buscava.

\footnotetext{
3 Idem, p. 54

4 Idem, p. 57.

5 Idem, p. 65.
} 
A cor no espaço

Só a partir de 1953 Cruz-Diez começa a fazer sua primeira série abstrata, de maneira intuitiva, sem uma intenção ou direção esclarecida. Para estes primeiros experimentos, novamente a cor o auxilia: são colagens com círculos e linhas de cores primárias. Sobre estes trabalhos, ele diz que sua principal referência foi a artista suíça Sophie Taueber-Arp, a qual também teve uma relevante pesquisa cromática abstrato-geométrica para a arte moderna europeia. As colagens logo dão lugar a relevos, pequenos pontos de cor que saltam ao espaço, que começam a se orientar no que viria a ser sua ocupação principal: "lançar a cor no espaço por meio da luz refletida". A ideia era dar animação ao plano e fazer suas cores refletirem ao seu redor do suporte físico, isto é, na parede. Estas obras eram projetos do que viriam a ser obras públicas. Algumas delas, inclusive, permitiam a manipulação do espectador (figura 02), algo ainda raramente explorado na arte. Pode-se dizer que as referências pictóricas da arte moderna para o artista aos poucos encontram a contemporaneidade ao saltar as composições planares para a terceira dimensão - que não era exatamente escultura, mas expansão do meio pictórico -, e, frequentemente, incluir o dado da interação do espectador - questões que não existiam na modernidade, que embarcou numa autonomia da obra de arte de modo a "depurá-la" todos os outros dados (da figuração ao espaço onde ela se insere, através da criação do cubo branco).

Naquele momento, a solução daqueles trabalhos ainda não estava clara em sua cabeça. Parecia-Ihe que a arte abstrata não poderia conferir o mesmo entendimento da pintura figurativa, que a experiência estética da abstração e da cor deixava de lado importantes aspectos humanistas que poderiam ser atingidos pela narrativa. Por isso as obras de Mondrian Ihe pareciam "frias e distantes", porque a investigação do plano pictórico pela abstração atingia motivos e camadas de leitura que já não ficavam mais tão evidentes no trabalho final para o "espectador comum". Era importante manter a relação com este através de algum aspecto inédito da obra - que viria a ser a interação através dos fenômenos cromáticos perceptivos que ele descobriu posteriormente.

A busca por se encaixar na História da Arte, por uma linguagem própria e por atingir o espectador se uniam na busca por um ineditismo, algo que ainda não figurasse nos livros de arte. A partir disso, ele começa a procurar o que há de particular em seu trabalho e se aprofundar nisso, como um exercício de construir um discurso próprio, ainda que sem deixar a afetividade de lado. Até que

6 Idem, p.68. 


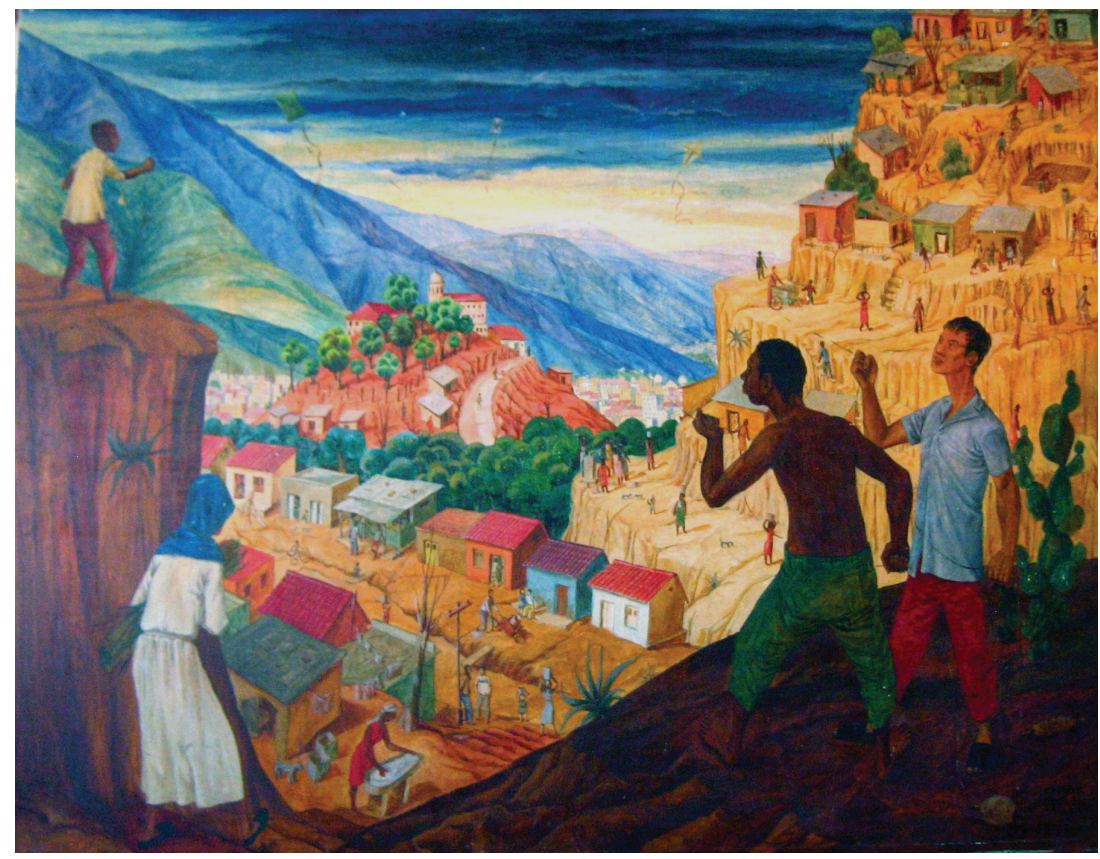

[Figura 01]

Carlos Cruz-Diez. El Papagayo Verde. 1949.

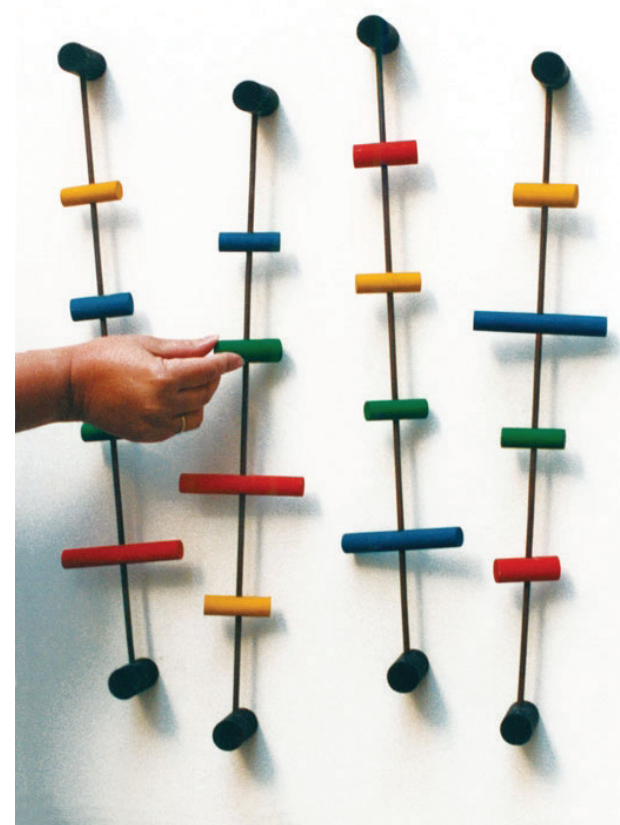

[Figura 02] Carlos Cruz-Diez. Proyecto Mural. 1954.

Acrílica sobre tela. $71 \times 55 \mathrm{~cm}$. Cruz-Diez Foundation, Houston.
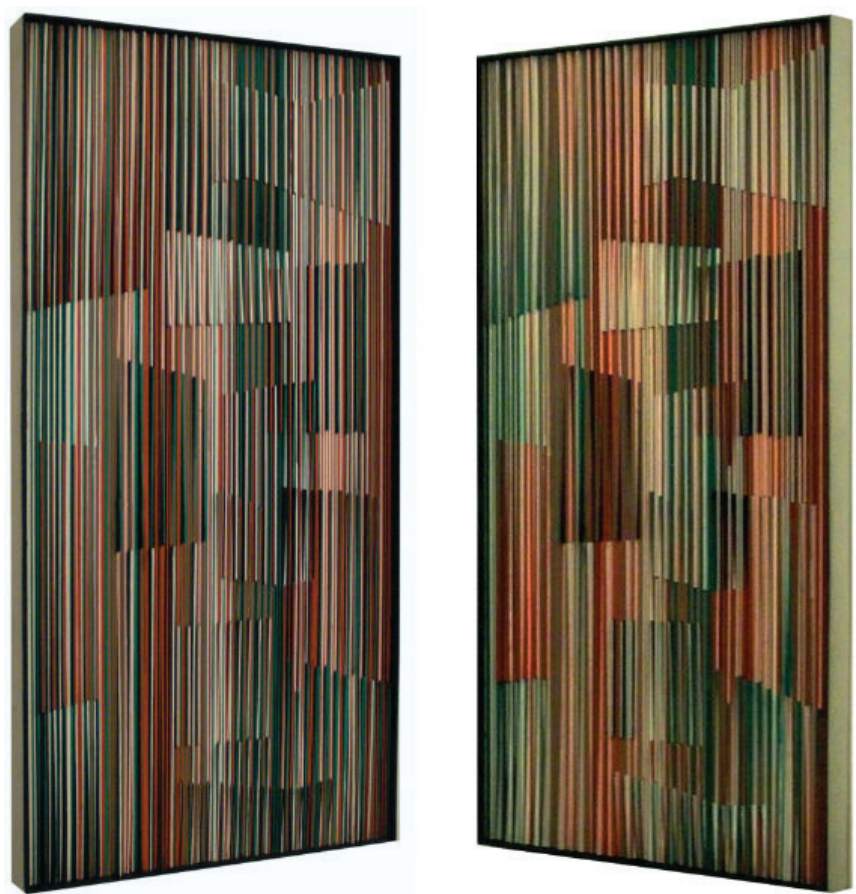

[Figura 03] Carlos Cruz-Diez. Fisicromía 2. 1959.

Papelão, caseína (Plaka) sobre compensado e moldura de madeira. $100.9 \times 51.2 \times 6 \mathrm{~cm}$. Coleção Daros Latinoamericana, Zurique. 
a resposta se revelou: o mundo da cor é o mundo da afetividade ${ }^{7}$. Na vontade de se aprofundar em seu próprio discurso, ele mergulhou no seu conhecimento da cor e em como utilizá-la para criar um evento estético inédito.

Entre 1955 e 1956, o artista se muda com sua família para a Europa, onde toma contato com o que foi considerado o início da arte cinética. Na Venezuela, ele havia tido pouquíssimo contato com arte abstrata, de modo que este contato no continente europeu produz uma virada em seu trabalho. Em meados de 1956, o artista retorna à Caracas, convencido que sua vontade de fazer a diferença na sociedade através da arte encontraria lugar nesta cidade. Neste período, ele produziu o seu primeiro Color Aditivo: duas faixas de cor finíssimas sobre fundo preto, uma vermelha e uma verde que, transpassadas, produziam opticamente o amarelo, que não estava pintado no quadro. Esta experiência leva ao início da série Fisicromías, que multiplicava esse fenômeno e criava um plano dinâmico. A construção de faixas de cores específicas produzia matizes que não estava fisicamente no quadro. Esta é a primeira série que inclui o dado do tempo. Esta foi uma descoberta crucial para Cruz-Diez: criar um fenômeno óptico no tempo, animar o plano da pintura (figura 03). O quadro literalmente se modifica com o movimento do nosso corpo diante dele e, consequentemente, com o movimento do nosso olhar, já que este nunca é fixo e estático num só ponto.

As Fisicromías são uma leve armadilha; um espaço no qual uma série de redes de cores interage para se transformar, gerar novas faixas de cores e invadir o espaço circundante entre as folhas verticais que cobrem o trabalho. Além disso, o movimento do espectador ou da fonte de luz também cria uma série de variações cromáticas que, como as que ocorrem no espaço real da paisagem, se repetem sem cessar a cada revolução do sol sem nunca serem exatamente iguais, pois a intensidade e o tipo de luz que os banha nunca serão idênticos. Daí o nome Fisicromías, do fato de colocar cor, cor física, em jogo. ${ }^{8}$

Em 1960, ele expõe a série Fisicromías no Museo de Bellas Artes de Caracas, mas sua receptividade é quase nula9 . O contexto do país não se associava aos problemas que o interessavam, de modo que "ninguém entendeu nada"10. Em outubro do mesmo ano, ele se transfere definitivamente para Paris, onde permaneceria até seu falecimento, em 2019, embora tenha retornado diversas vezes à América do Sul para realizar projetos e mesmo estabelecer seu segundo atelier no Panamá. Além de ter sido um movimento muito comum dos artistas latino-americanos deste período

\footnotetext{
7 Idem, p.73.

8 CRUZ-DIEZ apud SUARÉZ, Osbel. Carlos Cruz-Diez: Color Happens. Madrid: Fundación Juan March, 2009. p. 10

9 CRUZ-DIEZ, Carlos. Carlos Cruz-Diez conversa com Ariel Jiménez. São Paulo: Cosac Naify, 2014. p.109.

10 Ibidem.
} 
- transferir-se para Paris ou Nova York - havia a tradição de viajar à Europa desde o século XIX, através das Academias, e Paris era o principal destino, onde supostamente o ambiente artístico estava mais aberto a novidades.

A partir de Fisicromías, Cruz-Diez amplia o ol har para inúmeras possibilidades de animação do plano através dos fenômenos cromáticos. Os trabalhos vão aumentando de tamanho conforme ele aprimora as técnicas e materiais utilizados. Ele chegou a fabricar pequenas máquinas para auxiliálo na produção de suas obras. A partir dos anos 1960, ele já consegue produzir grandes painéis de Fisicromías, em materiais como PVC e alumínio.

Anos após a descoberta das Fisicromías, novamente em experimentos realizados no atelier, ele chega a suas Induciones Cromáticas, trabalhos nos quais a saturação de um determinado matiz produz o aparecimento de seu complementar nos intervalos das faixas, através do fenômeno da pós-imagem. Segundo o artista, o importante não era apenas ter descoberto o fenômeno, mas a possibilidade de tê-lo encontrado para enriquecer seu discurso ${ }^{11}$.

Pouco a pouco, Cruz-Diez “libera” a cor do suporte e até da materialidade para projetá-la no espaço através da luz. O domínio do campo fenomenológico foi apenas uma dessas maneiras de realizar esta vontade, e a luz acabaria por se revelar o principal veículo da projeção dessa cor etérea no espaço.

As Transcromías são mais um passo nessa direção. São obras tridimensionais onde se utilizam planos de filtros coloridos em diferentes montagens possíveis, conforme o material utilizado - acetato, acrílico, entre outros (figura 04). Aqui, trabalha-se ao mesmo tempo com a cor aplicada e o reflexo da luz, que faz com que a cor ocupe outro lugar que não apenas o objeto - o chão, a parede e até o corpo do espectador. A operação é parecida com a realizada em suas Cromosaturaciones (figura 05), ambientes saturados de cor através de filtros e/ou lâmpadas muito intensas. Existem nesses trabalhos menos um fenômeno cromático óptico e mais um arrebatamento pela cor, uma vontade de devolver ao mundo o que já seria dele em primeiro lugar, confirmando a frase de Hélio Oiticica: "Cor é a revelação primeira do mundo."

Dito isso, no final dos anos 1960, seu trabalho sai da galeria e ocupa o espaço público, provocando uma nova virada no seu trabalho. A importância da interferência urbana tem motivo na vontade de penetrar no cotidiano do espectador, de modo a criar um evento estético que "desautomatize" o seu olhar, criando a sensibilidade que ele buscava desde o início no "espectador comum",

11 Idem, p.157. 


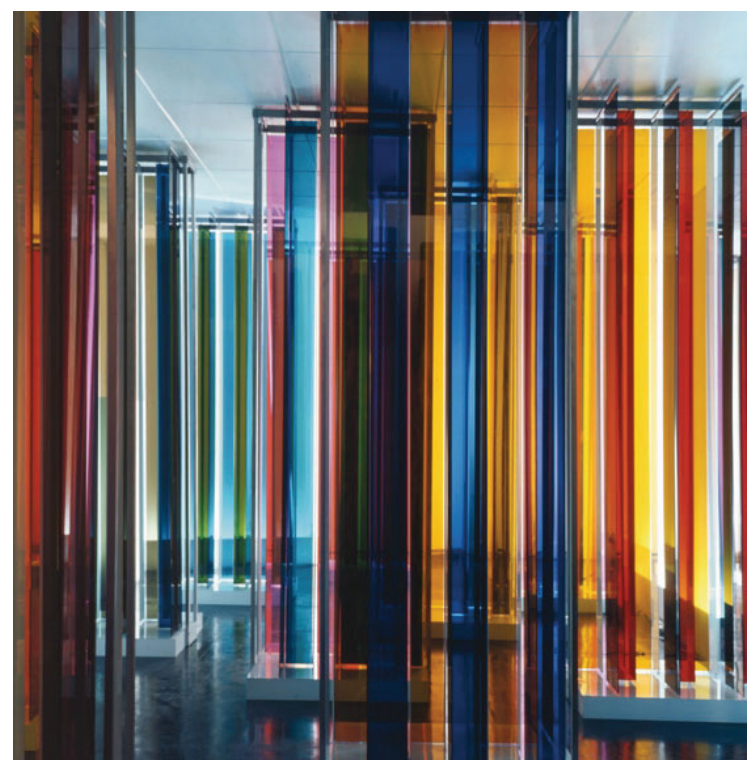

[Figura 04]

Carlos Cruz-Diez. Transcromía. 1969.

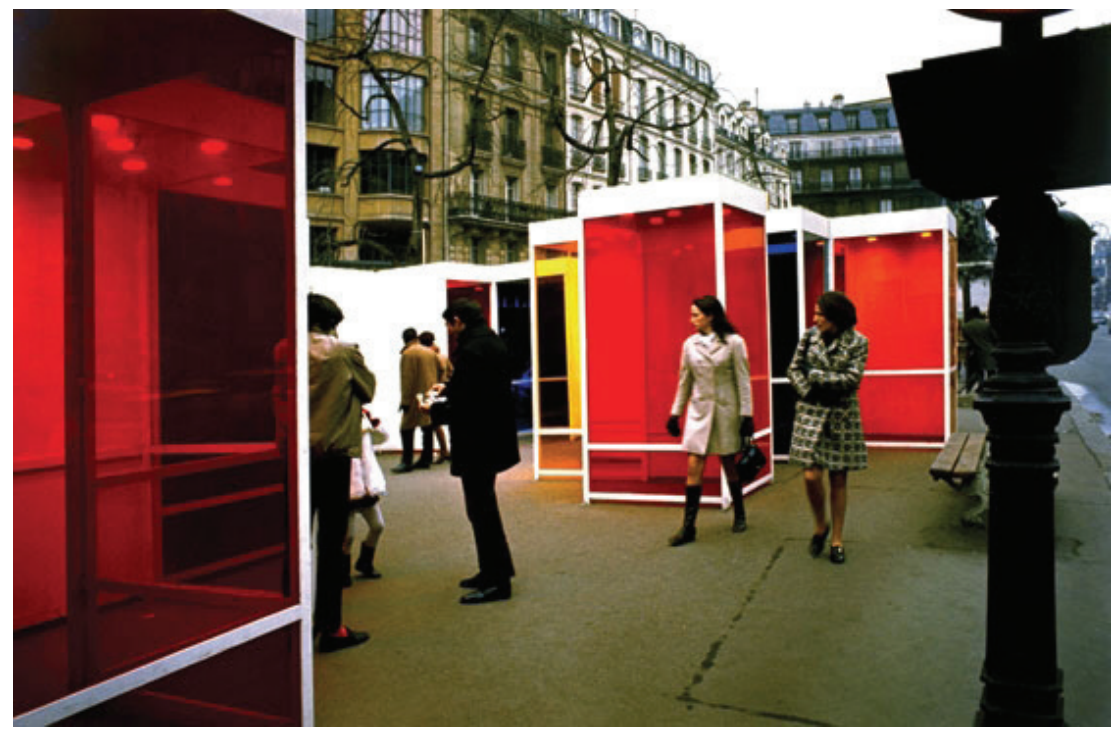

[Figura 05]

Carlos Cruz-Diez. Cromosaturación para un espacio público. 1969.

Cabines. $2.75 \times 1.20 \mathrm{~m}$ cada. Paris.

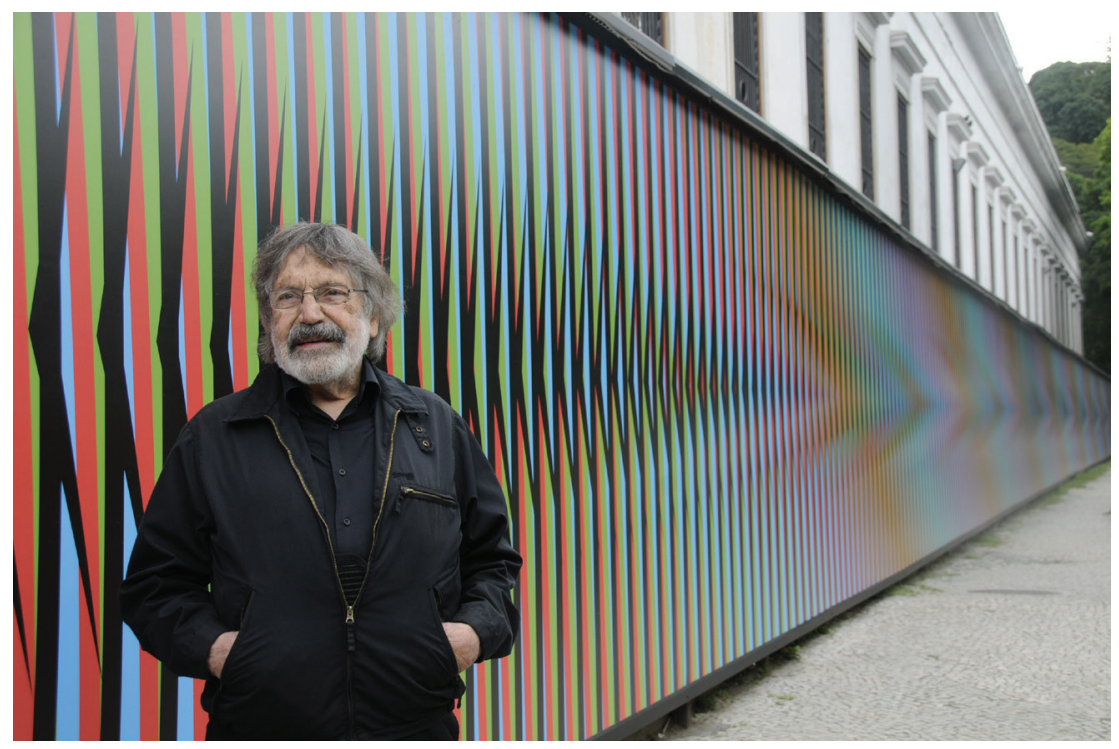

[Figura 06]

Carlos Cruz-Diez. Induction Chromatique Double Fréquence. 2013.

Tapumes. $2.5 \times 87$ m. Rio de Janeiro. 
aquele transeunte do espaço urbano acelerado e caótico. Esse evento era provocado pelos fenômenos perceptivos da cor, já aprofundados em suas obras indoor. A temporalidade da obra que já se percebia dentro da galeria se exacerba no espaço público, onde o corpo se movimenta naturalmente com rapidez - inclusive dentro de automóveis. A lógica da intervenção urbana é completamente diferente da contemplação no museu, com bancos em frente às obras, e essa temporalidade outra é o que interessa ao trabalho do artista. O fenômeno da cor se dá no tempo.

\section{Conclusão}

A vontade de se integrar ao cotidiano também encontrou lugar na integração de sua obra à arquitetura. Esta evidência demonstra a importância da experiência como programador visual na juventude e o legado do estudo da Bauhaus para seu pensamento artístico. No entanto, o artista se aproveita da velocidade da vida em espaços e edifícios públicos - fluxos de aeroportos, velocidade dos carros, movimentação de pedestres nas praças - para criar um evento estético que capte a atenção do transeunte e "enriqueça" seu cotidiano (palavra do artista), sem que ele precise necessariamente frequentar uma exposição.

A exemplo de uma de suas intervenções, em 2013, durante a reforma de abertura da casa Daros, no Rio de Janeiro, a mesma promoveu o programa "Meridianos", que consistia em encontros gratuitos entre artistas latino-americanos presentes na sua coleção e em ativações do espaço mesmo em reforma. Cruz-Díez realizou a intervenção Induction Chromatique Double Fréquence (figura 06) nos tapumes da casa, ativando-a mesmo antes de sua abertura oficial. A rua Ceneral Severiano, no bairro de Botafogo, é uma rua movimentada principalmente por carros. Ao passar diante da imagem, ela provocaria um acontecimento no olhar do espectador, de modo a "desautomatizar" o olhar coloquial para um evento estético. O trabalho oferece uma experiência cromática diretamente "no mundo" por assim dizer, sem a mediação de espaços sacralizados de arte. A arte que expande seus meios, ocupa espaços diferentes do espaço modernista idealizado, vai para o espaço público e frequenta o cotidiano das pessoas tem a potência de atingir todos os transeuntes, aquele que vai ou não ao museu, e de qualquer idade.

Suas premissas estavam em consonância com sua contemporaneidade: explorar a relação sujeito-obra; integrar a arte à vida; experimentar múltiplos meios e, em última instância, se inserir na História da Arte. A Arte Cinética se utilizou principalmente do movimento para alcançar estes princípios, mas Cruz-Diez mergulhou profundamente no universo das cores (teórico e prático) para 
alcançá-los. O alcance de suas interferências cromáticas no espaço público proporcionou uma solução dupla para seus objetivos: criar uma linguagem autêntica, compatível com seu meio, e reforçar o caráter social da arte, alterando a percepção da paisagem urbana pelo espectador.

\section{Referências bibliográficas}

CARVALHO, Laura. Arte contemporânea e os desdobramentos da cor. In: THE INTERNATIONAL ASSOCIATION INTERNATIONALE DE LA COULEUR CONGRESS, 2015, Tóquio. Disponível em: <http://www.procor.org.br/arte-contemporanea-e-os-desdobramentos-da-cor/> (Consultado em 15/11/2019)

CRUZ-DIEZ, Carlos. Carlos Cruz-Diez conversa com Ariel Jiménez. São Paulo: Cosac Naify, 2014.

Reflection on color. Madrid: Fundación Juan March, 2009.

DOHERTY, Gareth (org). New Geographies 3: Urbanisms of color. Harvard Graduate School of Design, 2011.

SUARÉZ, Osbel. Carlos Cruz-Diez: Color Happens. Madrid: Fundación Juan March, 2009. 